\title{
Ana Laura Lanteri
}

Doctora en Historia por la Universidad Nacional del Centro de la Provincia de Buenos Aires, y profesora y licenciada en Historia por la Universidad Nacional de Mar del Plata. Ha recibido becas y subsidios de investigación de la UNMdP y del CONICET. Actualmente (2011-2013) se desempeña como becaria posdoctoral del CONICET y como docente y colaboradora en las áreas de pedagogía e historia argentina de la UNMdP. Integra el Grupo de Investigación "Problemas y debates del siglo XIX" (UNMdP). Ha publicado artículos en revistas nacionales e internacionales y ha participado como ponente en diversos encuentros académicos. Su investigación versa sobre el sistema político de la "Confederación" argentina (1852-1862).

\section{Resumen}

Se realiza una relectura de la "Confederación" argentina (1852-1862) desde una perspectiva soslayada por los estudios específicos del periodo. Se focaliza en la convergencia de las dinámicas nacional y provincial para explicar la conformación del orden político. Se afirma que, en el hiato entre lo proyectado y lo realizado, un proceso de aprendizaje y de conformación político-institucional nacional se inició por entonces y se consolidó en las décadas siguien- tes. Se privilegia al Congreso como la institución desde la que se observa la problemática, en tanto ámbito de conformación de la dirigencia nacional y de la institucionalidad estatal. Pero la indagación lo trasciende, al considerarse el accionar y la interacción de los legisladores y del poder ejecutivo nacional y la respuesta de las elites políticas provinciales a las disposiciones allí tomadas.

Palabras clave:

"Confederación" argentina; elites políticas provinciales; poder ejecutivo nacional; congreso nacional; justicia federal.

Fecha de recepción: julio de 2011
Fecha de aceptación:

junio de 2012 


\title{
About Learning and the Political-Institutional Shaping of the Country. A Re-interpretation of the Argentinean "Confederation" (1852-1862)
}

\author{
Ana Laura Lanteri
}

$\mathrm{PhD}$ in History from the Universidad Nacional del Centro de la Provincia de Buenos Aires and Professor and B.A. in History from the Universidad Nacional de Mar del Plata. Recipient of Fellowships and Research Grants from UNMdP and CONICET. Currently (2011-2013) a Postdoctoral Fellow of CONICET and a teacher and collaborator in the areas of Education and Argentinean History of UNMdP. Member of the Research Group "Problems and Debates of the 19th century" (UNMdP). Has published articles in national and international journals and delivered papers at various academic meetings. Her research focuses on the political system of the Argentinean "Confederation" (1852-1862).

\begin{abstract}
The Argentinean "Confederation" (1852-1862) is te-interpreted from a perspective overlooked by specific studies on the period. It focuses on the convergence of national and provincial dynamics to explain the formation of the political order. It states that a learning process and national politico-institutional shaping began in the hiatus between the projected and the

actual, which was consolidated in the following decades. Congress is the institution from which the problem is observed as a sphere for shaping national leadership and state institutions. But the paper goes beyond this to consider the action and interaction of legislators and the executive branch and the response of provincial political elites.
\end{abstract}

Key words:

"Confederation"; provincial political elites; national executive branch; national congress; federal justice. 


\title{
Acerca del aprendizaje y la conformación político-institucional nacional. Una relectura de la "Confederación" argentina (1852-1862)
}

\author{
Ana Laura Lanteri
}

\section{INTRODUCCIÓN}

4 n las últimas décadas, la historiografía política iberoamericana reformuló sus principales interrogantes y renovó sus enfoques metodológicos y conceptuales sobre el proceso de conformación de los Estados nacionales durante el siglo XIX. A partir de una variedad de espacios geográficos y de periodos abordados con sus especificidades propias, diversos estudios han dado cuenta del carácter misceláneo del federalismo y el republicanismo en la región y del arduo trabajo que supuso su construcción. ${ }^{1}$

Desde un enfoque renovador para el caso argentino, José Carlos Chiaramonte sugirió un análisis alternativo a los estudios que habían considerado la "cuestión regional" como la de los obstáculos inter-

${ }^{1}$ El registro social de la política fue ampliado con abordajes que contemplaron, entre otras cuestiones, el análisis de sectores intermedios y subalternos, los campos "informales" de la política y los ámbitos de sociabilidad y que se abocaron a la revisión tanto de las trayectorias doctrinarias y las representaciones como de las prácticas y las redes de relaciones políticas y personales de los actores. Entre otros, Palacios (coord.), Ensayos, 2007, y Carmagnani (coord.), Federalismos, 1993. puestos en el camino de una organización nacional iniciada desde la disolución del vínculo colonial. En cambio, afirmó que en dicho proceso fuerzas provinciales contrapuestas - actuantes como Estados soberanos e independientes desde 1820-, cambiaron su orientación para que surgiese un Estado federal en 1853.2

En efecto, la Constitución nacional sancionada en dicho año definió una federación que se consolidaría por la delegación en el poder nacional de ciertas facultades por parte de los gobiernos provinciales. Como la provincia de Buenos Aires se negó a encolumnarse tras las demás en este sistema político, convivieron hasta 1862 dos Estados en el territorio de las ex Provincias Unidas del Río de la Plata: el de Buenos Aires y el de la "Confederación" de las provincias liderado por Justo José Urquiza (hasta entonces gobernador de Entre Ríos). Ambos Estados lucharon durante una década por consolidar sus estructuras económicas y político-institucionales y por obtener la unidad y supremacía nacional. ${ }^{3}$

\footnotetext{
${ }^{2}$ Entre otros trabajos del autor, Chiaramonte, Nación, 2004.

${ }^{3}$ Especialmente desde su segundo gobierno en Buenos Aires entre los años 1835 y 1852 , Juan
} 
Pese a representar una bisagra que articula la primera y la segunda mitad del siglo XIX en el proceso de conformación estatal nacional, esta etapa y, especialmente, la Confederación, han sido poco estudiadas por la historiografía argentina. En efecto, a diferencia de los importantes y renovados estudios sobre el Estado porteño, ${ }^{4}$ los trabajos que sobre aquella intentan realizar una mirada de conjunto son escasos. Además, fueron realizados en su mayoría con anterioridad a la década de 1990 , por lo que no participaron del clima

Manuel de Rosas, utilizando sus atribuciones de gobernador y las de delegado de las relaciones exteriores de las restantes provincias, había logrado inhibir la creación de un sistema político que se situase por encima de las soberanías provinciales. Pese a ello, la sanción del "Pacto Federal" en 1831 dio base jurídica a una Confederación que enlazó a las provincias en un orden político perdurable hasta 1852. El poder de Rosas encontró resistencias que finalmente precipitaron su derrota. En efecto, la acentuación del control político y su política económica y fiscal (que entre otras medidas suprimió la libre navegación de los ríos $y$, por ende, obstaculizó las operaciones directas con el exterior) provocó el descontento de diversos sectores. En 1851 Urquiza proclamó un "Pronunciamiento" por el que Entre Ríos retiró su delegación de las relaciones exteriores en Rosas y delineó un programa a seguir: sostener principios programáticos y crear y fomentar instituciones tutelares. En el mismo año se formó el "Ejército Grande" que finalmente derroró a Rosas en la batalla de "Caseros" en febrero de 1852. El periodo 1852-1862 es conocido entonces como la "Confederación" pese a haberse conformado un Estado federal, en adelante utilizamos el término sin comillas. A finales de 1861 la Confederación fue derrotada por las fuerzas porteñas en la batalla de "Pavón" y, meses después, Bartolomé Mirre asumió la presidencia, dando inicio a una nueva etapa de conformación estatal bajo la hegemonía de Buenos Aires.

"González, Civilidad, 2000; Lettieri, Construcción, 2006, y Garavaglia, Construir, 2007. de renovación de la historia política que referimos.

$Y$ a ello se suma que, a nuestro entender, las interpretaciones dadas dificultan la comprensión de la trama política e institucional de la Confederación. Tanto aquellos autores que enfatizaron la imposibilidad de sentar bases institucionales y políticas nacionales como los que, por el contrario, señalaron el éxito alcanzado en la organización nacional soslayaron una cuestión que creemos fundamental. $:^{5}$ prestaron poca atención a la convergencia de las dinámicas provincial y nacional para explicar la conformación del orden político del periodo. Estas visiones dieron así poco margen de participación a las provincias y a sus representantes, desdibujando su protagonismo en el proceso. ${ }^{6}$

En estas páginas se asume una postura intermedia entre ambas visiones al afir-

${ }^{5}$ Entre los primeros: Scobie, Lucba, 1964; Gorostegui, Organización, 1972; Páez, Derrumbe, 1984; Angueira, Proyecto, 1989, y Oszlak, Formación, 1997. Entre los segundos: Ruiz, Centenario, 1952; Macchi, Primera, 1979, y Bosch, Urquiza, 1980.

${ }^{6} \mathrm{El}$ enfoque que asumimos es tributario de las nuevas miradas sobre el periodo 1852-1880 desarrolladas en los últimos años. Desde una variedad de especificidades locales/provinciales interesantes estudios atienden a la forma en que el proceso de construcción estatal nacional afectó el desarrollo de las provincias y recíprocamente, a la medida en que los intereses de las elites provinciales fueron contemplados en las estrategias de las autoridades nacionales. Por la amplia producción, nos permitimos citar sólo la obra de reciente aparición Bragoni y Míguez (coords.), Nuevo, 2010 y un balance crítico en Míguez, "Gestación", 2012. Asimismo debe ser advertido que algunos trabajos recientes han señalado los avances en la conformación estatal nacional del periodo: Buchbinder, Caudillos, 2004; Garavaglia, "Rentas", 2010, y Mega, "Confederación", 2010. 
marse que, en el hiato entre lo proyectado y lo realizado, un proceso de aprendizaje y construcción político-institucional nacional se inició en la Confederación y se consolidó en las décadas siguientes. ${ }^{7}$ Aunque mucho menos eficaz de lo que sus autoridades esperaban, este fue más importante para la conformación estatal nacional -tanto coetánea como posterior- de lo que las interpretaciones históricas describieron. Postulamos que, por la sociabilidad de la política y el andamiaje institucional que se fue construyendo, las provincias comenzaron a entenderse y a asumirse en una forma federal y republicana y las autoridades a constituirse en una dirigencia política con proyección nacional.

El enfoque elegido privilegia al Congreso nacional -que funcionó en Paraná, la capital de la Confederación, entre 1854 y 1861-, como la institución estatal desde la que se observa la problemática. Se lo aborda como un ámbito efectivo de encuentro, aprendizaje e integración de las elites políticas provinciales en el nuevo sistema político. $Y$, por ende, de conformación de la dirigencia nacional y de la institucionalidad estatal. Pero la indagación trasciende dicha institución. Ello es porque se considera el accionar concreto y la interacción de los legisladores y del poder ejecutivo nacional y la respuesta de las elites políticas provinciales a las disposiciones tomadas en el Congreso.

En primer lugar, se estudian los rasgos centrales del funcionamiento institu-

${ }^{7}$ Este artículo constituye una sintesis de algunos problemas tratados en los capítulos 2 y 4 de mi tesis doctoral, Lanteri, "Ideal", 2011, ditigida por los doctores Valentina Ayrolo y Eduardo José Míguez. Agradezco los valiosos comentarios realizados por los evaluadores anónimos de la revista. cional de dicho recinto legislativo. Luego, se profundiza el análisis desde la labor legislativa desarrollada y se presentan algunos ejemplos sobre su implementación práctica, que creemos centrales para problematizar el proceso estudiado. Especialmente, referimos al papel y el accionar de la justicia federal. A diferencia de aquellos autores que aludieron a su falta o casi nula actividad, mostramos su alcance y funcionalidad como poder estatal e institución para la nacionalización de las provincias. $^{8}$

\section{LAS PROVINCIAS EN UN MARCO INSTITUCIONALIZADO: FUNCIONAMIENTO GENERAL DEL CONGRESO NACIONAL}

Tras la secesión de Buenos Aires en septiembre de 1852, los representantes de las restantes provincias integradas en la Confederación se aglomeraton en el "Congreso General Constituyente" que sentó las piedras angulares del nuevo juego político nacional. A comienzos de 1854 se realizó el escrutinio de la elección presidencial y, luego de que las nuevas autoridades asumieron sus cargos, dicho Congreso cerró sus sesiones.? Elegido presidente, Justo José de Urquiza, se dispuso enseguida a dar nuevos pasos tendentes a la organización estatal.

\footnotetext{
${ }^{8}$ Los autotes referidos son Bosch, "Poder", 1964 ; Zavalía, Historia, 1920, y Gorostegui, Organización,

"Al hacerlo dictó un manifiesto a "los pueblos de la Confederación" donde los diputados dieron cuenta de la obra realizada y manifestaron su fe en un futuro bajo la "obediencia absoluta a la constitución". Cámara de Diputados de la Nación, Poder, 1937, t. I, segunda parte, pp. 1147-1150.
} 1972. 
Por una parte, para contrarrestar el peso diplomático porteño y lograr que la Confederación fuese reconocida como Estado soberano, envió a Juan Bautista Alberdi en una misión a Francia e Inglaterra (en donde permaneció hasta 1860 , como analizaremos luego). La elección de Alberdi no fue casual. En efecto, ya se había recapitalizado su discurso cuando sus postulados quedaron plasmados en las normas constitucionales nacionales de 1853. En sus "Bases" escritas en 1852 había enunciado que la soberanía residía "originariamente" en la nación y con ello produjo un viraje discursivo concluyente: el pasaje del sistema confederal a un Estado federal.

Su "república posible" se asentó en la legitimidad del poder limitado para, a partir de ese afianzamiento institucional del poder, transformar a la sociedad nacional. En este marco señaló que el poder ejecutivo nacional era el más importante en la administración estatal. ${ }^{30}$ Según Alberdi, sería un presidente constitucional con las facultades de un rey, el límite a su poder era el plazo de seis años de duración de su mandato que, por otra parte, no era ni hereditario ni renovable a pesar de las muchas atribuciones que concentraba. Además, estaba equilibrado por el poder judicial y dos cámaras legislativas que representaban a todas las provincias (en la de senadores de manera igualitaria y en la de diputados en forma proporcional). ${ }^{11}$

${ }^{10}$ Alberdi, Bases, 1991. Para un análisis de su pensamiento véase especialmente Canal, Constitución, 1986; Roldán, "Cuestión”, 2010, y Goldman (ed.), Lenguaje, 2008.

${ }^{11}$ Los condicionamientos económicos y de edad, las fuentes de legitimidad y la duración de los cargos difirieron entre senadores y diputados. El Senado
El discurso de la nación sirvió entonces para legitimar la construcción del Estado que emprendió el personal político federal. Al igual que en otros espacios iberoamericanos, la representación política y la división de poderes fueron tanto principios que sirvieron de eje para configurar la nueva legitimidad política como mecanismos de gobierno. ${ }^{12}$ Como advertiremos enseguida, en este marco se establecieron complejas relaciones entre los poderes estatales.

Además de buscar apoyo extranjero, Urquiza procuró afianzar su poder político apuntalando mecanismos de centralización y de control ideológico. Para ello viajó en marzo a Córdoba, una provincia que le permitió tener visibilidad política por fuera del Litoral, región donde había consolidado su poder. Su estrategia era ganar desde allí apoyos provinciales y garantizar elecciones satisfactorias para el Congreso nacional pronto a reunirse en mayo.

El Congreso, como espacio soberano ubicado en la capital, posibilitaba al ejecutivo nacional acercarse y disciplinar a los poderes provinciales soslayando un diálogo directo con los gobernadores en sus

representaba a las elites provinciales mientras que la soberanía popular quedaba expresada en la Cámara de Diputados. Los senadores eran elegidos por las legislaturas provinciales a pluralidad de sufragios, debían tener 30 años de edad, haber sido seis años ciudadanos de la Confederación y poseer una renta anual de 2000 pesos y permanecían nueve años en sus puestos. Los diputados eran elegidos por elección directa, debían tener 25 años de edad y cuatro años de ciudadanía en ejercicio, duraban cuatro años en sus cargos y se renovaban cada dos años por mitad.

${ }^{12}$ Entre algunas de las obras de referencia ineludible sobre el tema se encuentran Sabato, Ciudddania, 1997, y Annino, Historia, 1995. 
respectivas provincias, que podía resentir la base de su legitimidad política. Y, además, le permitía hacer uso de un mecanismo como la conexión diplomática, que estaba aceitado por décadas de pactos interprovinciales (los más importantes, en efecto, fueron considerados como antecedentes en el propio preámbulo de la Constitución nacional).

Sus esfuerzos por reunir al Congreso dieron testimonio del enlace entre los procesos constitucionales formales y las circunstancias y voluntades políticas concretas. Las sesiones finalmente se inauguraron el 22 de octubre de 1854, casi cinco meses después de la fecha pautada, porque recién por entonces se logró conformar el quórum legal para sesionar (estipulado como la mitad más uno de los miembros de cada Cámara legislativa). Y por ley, como esas sesiones sólo duraron hasta el 3 de diciembre, se decidió declararlas extraordinarias. ${ }^{13}$

Aunque la mayoría de las provincias había elegido a sus diputados y senadores en la fecha estipulada, tensiones políticas entre los ejecutivos y las legislaturas de algunas de ellas, como La Rioja, Córdoba y San Juan y la falta de recursos para costear el traslado a Paraná, demoraron la instalación. ${ }^{14}$ Además de estas circunstan-

${ }^{13}$ El gobierno nacional estuvo especialmente preocupado por dejar una buena impresión en las provincias de lo realizado en el Congreso. El vicepresidente instó a los senadores a que estuvieran bien informados de todos los asuntos y que los despachasen con rapidez antes del cierre de las sesiones "para que los pueblos viesen que a pesar del poco tiempo que habían funcionado las Cámaras lo habían sabido aprovechar". Cámara de Diputados de la Nación, Poder, 1937, t. II, p. 97.

${ }^{14}$ Datos en Miguel Díaz de la Peña a Juan María Gutiérrez, Tucumán, 19 de agosto de 1854, y Juan cias, el obstáculo más frecuente para lograr el quórum fue la preferencia que los elegidos tuvieron por sus negocios particulares, por permanecer en sus puestos políticos provinciales o, simplemente, por optar representar a otra provincia que los había elegido en forma simultánea. ${ }^{15}$

Las circunstancias de 1854 no fueron una eventualidad política sino más bien una norma. En efecto, el Congreso nacional sesionó hasta diciembre de 1861 en un complejo marco institucional. Su funcionamiento se vio especialmente afectado por las dificultades antes mencionadas que le impedían conformar el quórum legal pero, además, por la falta de personal administrativo que pudiera agilizar su labor. ${ }^{16}$

No obstante, dicho recinto fue un puesto privilegiado desde el que distintos legisladores lograron extender el poder y los intereses de su familia. Claro que dicha situación se hizo más tangible para muchos actores luego de 1854, cuando el Congreso siguió funcionando con regularidad y las instituciones creadas -algunas

del Campillo a Juan María Gutiérrez, Córdoba, 1 de agosto de 1854, ambas en Biblioteca del Congreso de la Nación, Archivo, 1981, t. IV, p. 67 y t. III, p. 54, respectivąmente.

is Para ser legislador nacional no había requerimientos de nacimiento ni residencia en las provincias a representar. Hemos tratado el problema de la representación política en Lanteri, "Unos", 2011.

${ }^{16}$ Dicho quórum fue bastante reducido durante el periodo. Como muestra valga citar que en 1857 el Senado sesionó con un promedio de casi siete senadores menos de la composición reglada por la Constitución nacional mientras que, en 1861, lo hizo con poco más de diez menos. Y la Cámara de Diputados con cifras más parejas: en 1857 con un promedio de 11.13 diputados y en 1861 de 12.12 menos que lo estipulado. 
de las que examinaremos enseguida-iban canalizando los vínculos entre los poderes provinciales y el poder central. Si bien las distintas situaciones provinciales y personales nos impiden hacer una conclusión general, podemos señalar la progresiva consolidación del espacio de poder nacional gracias a la delegación de los diputados allí reunidos. ${ }^{17}$

En efecto, una cuestión que debe advertirse para explicar el bajo quórum del Congreso es su estrecha vinculación con una cualidad central del personal político federal durante el periodo: la superposición y circulación de funciones nacionales y provinciales, sobre la que volveremos enseguida. Muchas veces los legisladores no asistieron a las sesiones por estar desempe-

\footnotetext{
${ }^{17}$ Algunos testimonios de personas que quisieron ser legisladores durante el periodo en de Wenceslao Díaz Colodrero a Juan Gregorio Pujol, Paraná, 19 de agosto de 1859; de Juan de Dios Usandivaras a Juan María Gutiérrez, Salta 8 de mayo de 1855 y de Salvador María del Carril a Manuel Taboada, Paraná, 20 de noviembre de 1857; Taboada, Taboada, 1937, t. III, pp. 274-275; Pujol, Corrientes, 1911, t. IX, y Biblioteca del Congreso de la Nación, Arcbivo, 1981, t. IV. Algunos ejemplos del personal político cuyas trayectorias estudiadas en mi tesis doctoral revelan la ampliación del rango de influencia de sus familias y, en este marco, la participación de algún miembro de estas o de ellos mismos en el Congreso: Tomás Guido, Facundo Zuviría, Juan del Campillo, Benjamín Victorica, Ramón Gil Navarro, José Roque Funes y Domingo Navarro. Los Sánchez de Bustamante (analizados por Paz, "Gobierno", 2003) y los González (analizados por Bragoni, Hijos, 1999) son otros casos ilustrativos. Botana señaló tempranamente -en especial respecto del periodo abierto en 1880 - que la participación en el Congreso daba la posibilidad de favorecer el ingreso de parientes y aliados políticos en la administración nacional en expansión. Botana, Orden, 1977.
}

ñando alguna otra función en la administración nacional en la misma Paraná o en las provincias. Ellos mismos se mostraron especialmente preocupados por esta situación y tomaron diversas medidas que evidencian que había interés en mantener al Congreso como un espacio político común.

Por una parte, incorporaron en los reglamentos internos de ambas Cámaras pasos rigurosos a seguir en caso de inasistencia o renuncia de los legisladores, que incluyeron hasta multas en dinero. $Y$ desde el primer presupuesto anexaron el cobro de la "leguada" (una suma extra de dinero acorde con la distancia que recorrían desde el territorio en el que residían hasta Paraná). ${ }^{18}$ Por otro lado, sancionaron algunas leyes, como la que declaró incompatible el cargo de ministro con el de legislador en 1856 y la que dispuso que los legisladores debían tener permiso de su Cámara para aceptar o retener cualquier empleo del ejecutivo nacional en 1857.

Un repaso somero de las discusiones suscitadas por la aprobación de esta última y por el rechazo del Congreso al veto que el poder ejecutivo nacional intentó hacerle será de utilidad para nuestro análisis. Ello es porque revela un ajuste de atribuciones y deberes entre ambos poderes estatales y entre los niveles de poder provincial y nacional fijados en la Constitución nacional. Dichas discusiones sobre los alcances del régimen político nacional son por lo demás interesantes para vislumbrar la manera en que se fueron modelando los

\footnotetext{
${ }^{18}$ Los reglamentos y la discusión sobre la "leguada" en Cámara de Diputados de la Nación, Poder. 1937 , t. II, pp. 246-291, y t. IV, pp. 298-299, respectivamente.
} 
vínculos y esferas de acción de cada uno de estos. ${ }^{19}$

Bajo el argumento de que era inconstitucional que el Congreso decidiese sobre el contenido de la ley porque ello correspondía a las provincias -a los electores de los legisladores-, el poder ejecutivo nacional intentó vetarla. ${ }^{20} \mathrm{Y}$ apelando también a la Constitución nacional, el poder legislativo rechazó el veto objetando su uso en un caso en que no estaba en peligro la paz

${ }^{19}$ En adelante el documento del veto y las discusiones en Cámara de Diputados de la Nación, Poder, 1937, t. III, pp. 654-661.

${ }^{20}$ Conviene referir aquí a los procedimientos pautados. Al igual que en Estados Unidos, el trabajo del Congreso se organizó en comisiones. Ellas eran en la Cámara de Diputados las de Negocios Constitucionales y Legislación, Culto e Instrucción Pública, Peticiones y Negocios Extranjeros, Guerra y Marina y Hacienda. Y, en el Senado, las de Guerra y Marina, Hacienda, Interior y Peticiones y Negocios Constitucionales. Aprobado un proyecto de ley por la Cámara de su origen, pasaba a la discusión de la otra Cámara -que hacía las veces de revisora- y, una vez aprobada por ambas, pasaba a examen del poder ejecutivo nacional. Si este lo aprobaba la promulgaba como ley. Caso contrario -es decir si era vetada por el ejecutivo- pasaba a nuevo examen de ambas Cámaras y si nuevamente era aprobado por dos tercios en cada una de estas, la ley se promulgaba igual. Pero, si ante el veto presidencial, el proyecto volvía a la Cámara de origen y lo rechazaba o lo aprobaba pero no ocurría lo mismo con la Cámara revisora, la ley no podía ser vuelta a tratar durante todo el periodo legislativo. La comisión redactora de la Constitución nacional afirmó al respecto en su informe de 1853 que "su mente había sido establecer una especie de equilibrio entre ambos poderes en lo tocante a la ejecución y sanción de las leyes". El artículo concedía al ejecutivo un veto pero limitado, puesto que un proyecto de ley que él rechaza, aun podía ser sancionado y ejecutado sin su asentimiento. Cámara de Diputados de la Nación, Poder, 1937, t. I, segunda parte, p. 943. pública. Compararon en este sentido la gran cantidad de vetos que Urquiza había realizado hasta entonces con los pocos dados en Estados Unidos, Chile y Brasil. También se encargó el Congreso de destacarle al presidente que tenía jurisdicción exclusiva sobre sus miembros.

Una vez sancionada la ley, se gestionaron 42 permisos para ocupar y/o retener empleos del ejecutivo nacional. ${ }^{21}$ Muchos legisladores se opusieron a otorgar licencias porque pensaron que atentaría contra la propia conformación e independencia del poder legislativo. Sin embargo, otros consideraron que debían darse todos los permisos solicitados para fortalecer las diversas áreas de formación estatal.

Finalmente reconocieron la importancia de no alterar el frágil orden administrativo al restarle personal idóneo al gobierno nacional. Y ponderaron también el fortalecimiento de este último por encima de los poderes provinciales, lo que redundó en beneficio del fortalecimiento del aparato estatal. Negaron entonces la posibilidad a algunos de sus pares de licenciarse para ocupar cargos en las provincias mientras que dieron permiso a otros para desarrollar funciones en áreas para las que había pocos hombres cualificados.

Esto último siempre y cuando no fuesen a la vez empleados administrativos del propio Congreso. Como anticipamos, encontrar personal idóneo para atender sus diversas tareas fue muy dificultoso y los legisladores no estuvieron dispuestos a que desempeñaran funciones en otras dependencias estatales. ${ }^{22}$ Se transparentó así

21. En adelante, las discusiones consúltense en ibid., t. II, pp. 1150-1191.

${ }^{22}$ Según los reglamentos internos, el personal de cada Cámara debía, entre otras actividades, mante- 
una situación de reserva de atribuciones y prerrogativas del poder legislativo, sin que ello implicara desatender la conformación de una administración nacional.

El vínculo establecido entre ambos poderes estatales en el Congreso plasmó la concepción alberdiana de la armonía de un sistema federal con un ejecutivo fuerte. Este último trató de incidir en la aprobación de la ley que acabamos de analizar. Pero además, según hemos podido advertir en nuestra investigación doctoral, lo hizo en el caso de muchas otras y tuvo injerencia también en otros niveles del desarrollo institucional del Congreso, como la selección de candidatos para ocupar las bancas. ${ }^{23}$

Pese a ello, las provincias y sus representantes no resignaron su poder y percibieron al recinto legislativo como un espacio propicio para la conformación de una institucionalidad estatal que las integrase. Incluso, la injerencia del ejecutivo no fue considerada por muchos de los legisladores -quienes, por ejemplo, en el caso analizado sugirieron dar todos los permisos- como un elemento disolvente.

Por el contrario, en un marco de transformación político-institucional como el estudiado, encontraron en él un mecanismo para consolidar el entramado institucional y hacer así viable la organización

ner el aseo y el orden del recinto, reproducir las discusiones, cuidar el archivo, recibir los pedidos y notas de legisladores y del ejecutivo nacional y mantener el orden público en la sala en el momento de las sesiones. En especial, no se pudo contar con taquígrafos que desarrollaran su actividad -que era transcribir las discusiones y enviarlas para su impresión-con regularidad hasta los últimos periodos legislativos. Ibid., t. II, pp. 157-160, 246-291 y 301.

${ }^{23}$ Hemos desarrollado este punto en Lanteri, "Conformación", 2010, y "Provincias", 2011. nacional. Dicho ajuste de atribuciones entre el poder ejecutivo y el legislativo -y luego observaremos también con el poder judicial- fue conformando la dirigencia nacional.

Hubo otras escenas que se orientaron en este sentido. Las discusiones suscitadas por la presentación de los presupuestos nacionales, por ejemplo, ilustran con claridad lo que afirmamos. La ley que acabamos de analizar fue complementada en 1857 con otra que estableció que dichos presupuestos y las memorias ministeriales que los acompañaban debían ser publicados por el poder ejecutivo nacional dentro de los 20 días luego del inicio de cada periodo legislativo sin excepción.

Motivaron la ley las reiteradas demoras en cumplir esta tarea, que condujeron además a que el Congreso utilizara uno de los resortes institucionales que le permitía balancear el peso del poder ejecutivo nacional: las interpelaciones. ${ }^{24} \mathrm{Al}$ respecto, el ministro de Hacienda - que había sido interpelado en 1856-, comentaba a uno de sus pares sobre su accionar:

Estoy haciendo ahora la Memoria que he de presentar a las Cámaras, que a juzgar por lo

${ }^{24}$ La Constitución nacional había establecido que el poder ejecutivo nacional estaba encargado de confeccionar los presupuestos nacionales y sujetarlos a aprobación del Congreso. Junto con ellos, los ministros de cada ramo debían adjuntar una memoria de su accionar del periodo legislativo anterior. El nexo entre política y economía en torno a la elaboración de los presupuestos ha sido analizado por Carmagnani para el caso mexicano. Los valores materiales del gasto público podían transformarse en valores inmateriales perseguidos al nivel de derecho, porencia, representación exterior, justicia, cultura y prosperidad económica de sus ciudadanos. Carmagnani, Estado, 1994, especialmente pp. 56-66. 
que he escrito será un largo cuento de viejas. Cuando hablaba con seriedad la verdad pura. No les ha parecido bien mi franqueza; tal vez ahora tenga mejor suerte. La Memoria del Ministerio tiene que ser, aunque no quiera, una justificación de la del año pasado. ${ }^{25}$

Luego de las observaciones citadas, agregó que si no trazaba dicha memoria perdería credibilidad y que los legisladores estarían muy disgustados al saber que tampoco ese año cobratían sus sueldos por el precario estado de las finanzas nacionales. El pasaje muestra las dificultades existentes en la regularización de la administración estatal. Y, también, la voluntad del poder ejecutivo nacional de acreditarse ante los representantes de las provincias, legitimando su accionar aunque ello implicase darles información que no se condecía a la realidad de la Confederación. Pese a fomentar dicha imagen, no contestó a la ley.

En efecto, en 1858 se produjo otra interpelación de la Cámara de Diputados por una nueva demora en los plazos de entrega del presupuesto pero, esta vez, recayó sobre todo el gabinete. ${ }^{26}$ Las situaciones aludidas evidencian también la

${ }^{25}$ De Juan del Campillo a Juan María Gutiérrez, Paraná, 23 de abril de 1857, en Biblioteca del Congreso de la Nación, Arcbino, 1981, r. IV, p. 282.

${ }^{26}$ Allí, los ministros se negaron a rendirles cuentas a los legisladores, cuando fueron cuestionados sobre situaciones que creían estrictamente relativas a sus atribuciones constitucionales (tales como subdividir el trabajo presupuestario en áreas para agilizarlo). Y luego de un intercambio de palabras se retiraron con lo que el Congreso dio por finalizada la interpelación. Interpelación en Cámara de Diputados de la Nación, Poder, 1937, t. III, pp. 80-108. intención de los legisladores de mantenerse informados y de poder participar de la administración nacional. Estuvieron especialmente preocupados por el estado de desorganización del gabinete que les impedía conocer, ordenar y poder limitar el uso que se hacía de los recursos federales. ${ }^{27}$ Además, para las provincias era muy difícil la tarea de darse consistencia estatal sin participar de la estructura federal. Por ejemplo, los legisladores manifestaron en distintas ocasiones que las autoridades de las provincias que representaban les habían insistido en la necesidad de incrementar la partida presupuestaria de "subsidios", por su frágil estado financiero y administrativo. Incluso más: mocionaron en ocasiones para que el ejecutivo nacional invirtiese con preferencia en dichas subvenciones los magros recursos de los que se disponía. ${ }^{28}$

${ }^{27}$ Por citar otros ejemplos. Los legisladores buscaron mejorar la situación edilicia del Congreso y su propia formación erudita y labor legislativa. Decidieron sancionar una ley en 1859 que incorporó una partida para la compra de libros para formar una biblioteca del Congreso, pero el poder ejecutivo nacional decidió realizar un nuevo veto. Adujo que la inversión de la suma era su atribución exclusiva y que era más urgente atender otros ramos administrativos. El Congreso optó por rechazarlo, por lo que la biblioteca se inauguró unos meses después. Por otra parte, en ocasión de un pedido de crédito suplementario en 1859 para cubrir los gastos de las legaciones enviadas a Roma, Brasil y Paraguay, los legisladores se quejaron de no haber sido comunicados sobre ello. Y cuando recién aprobaron el crédito el ministro del ramo fue a darle las debidas explicaciones al Congreso. Ibid., c. III, pp. 672-679.

${ }^{28}$ En efecto, las sucesivas medidas tendentes a revertir la precaria situación económica fueron inviables. La bancarrota de los ingresos genuinos, la falta de crédito público de la Confederación y los emprés- 
¿Cómo se ideó entonces la construcción de una estructura estatal nacional sobre un sustrato de provincias con escasos recursos económicos y humanos?, ¿cuáles fueron los principales temas a los que se atendieron? Y, lo que es de importancia mayor para comprender la viabilidad federal de la Confederación, ¿qué respuesta tuvieron las provincias a dicha construcción?

En un contexto de metamorfosis política como el estudiado, la invención de leyes que debían servir de marco en una nueva configuración de la estructura y de la legitimidad estatal fue parte de un proceso sin una fórmula única y cuyos efectos sobre las esferas política y socioeconómica eran en gran parte impredecibles. Los políticos de la Confederación, que no eran personas ajenas al escenario nacional, creían en su espíritu formativo.

El análisis del perfil sociopolítico de las 203 personas que ocuparon los puestos estatales más importantes reveló su vasta trayectoria previa en defensa de la "unidad nacional". Asimismo, puso en evidencia sus cualidades profesionales y su circulación y superposición de funciones políticas, militares, judiciales y legislativas tanto anterior a 1852 como entre dicho año y $1861 .{ }^{29}$ Esta última cualidad -la superposición de cargos- atentaba con-

titos tomados con enormes intereses, evidenciaron la incapacidad para sostener la administración de gobierno. Una síntesis sobre los avatares del sistema económico en Schmit, Historia, 2008, pp. 152-160. Sobre los subsidios véase Cámara de Diputados de la Nación, Poder, 1937, t. rv, especialmente p. 496.

${ }^{29}$ Una síntesis de las trayectorias públicas y privadas individuales y familiares, de las redes de relaciones y de las cualidades y atributos de poder de dicho personal en Lanteri, "Confedetación", 2013. La reconstrucción fue realizada con base en diccionarios histó- tra el principio republicano de división e independencia de poderes $\mathrm{y}$, como advertimos, afectó la conformación del quórum del Congreso.

Pero esta indiferenciación entre las esferas del poder y la experiencia adquirida en la primera mitad del siglo XIX facilitó en la práctica la construcción institucional estatal y la conectividad de la dirigencia nacional. La conformación de dicha dirigencia exigió entonces recapitalizar y unificar un personal diverso que sin embargo tenía su sustrato común en la experiencia de los estados provinciales autónomos (y, en el caso de algunos, en las "Guerras de Independencia" de las primeras décadas del siglo).

Más allá de sus divergentes itinerarios -que no son materia de este trabajo-, habían adquirido empíricamente entrenamiento y saberes en el manejo de la actividad política y militar y reorientaron dicho bagaje corporizándolo en el nuevo

ricos, listados militares, registros oficiales y bibliografía que por cuestiones de espacio no son citados. Valga como muestra que sobre los 149 legisladores que actuaron entre 1854 y 1861 , antes de 1852 , al menos 105 había desarrollado actividades al servicio de diversos gobiernos provinciales y, entre ellos, 50 formaron parte de Legislaturas, cinco fueron gobernadores entre 1840 y 1852 y o quince fueron diputados al Congreso General Constituyente (1852-1854). Entre 1854 y 1861 , más de la mitad de los congresistas actuó en los gobiernos provinciales -entre ellos al menos 27 fueron ministros de gobierno y/o 21 fueron gobernadores-mientras que 20 cumplieron funciones ministeriales nacionales, al menos un número igual formó parte del ejército nacional, diez fueron miembros de la Suprema Corte de Justicia y/o 42 cumplieron diversas misiones o empleos al servicio del ejecutivo nacional para los que debieron obtener permiso desde 1857. Finalmente cabe ser destacado que más de $40 \%$ fueron comerciantes y/o hacendados. 
sistema político nacional. Por ello, optaron por proyectar una legislación que conjugó la adecuación a los mandatos constitucionales y una fuerte voluntad centralizadora y modernizadora con la experimentación y la respuesta a necesidades y cuestiones coyunturales.

Según surge del análisis general de las 292 leyes que finalmente fueron sancionadas entre 1854 y 1861, la centralización y modernización administrativa, rentística, judicial y militar y el control ideológico sobre las provincias fueron pensados como los principales recursos sociopolíticos y económicos de dominación y ejercicio del poder.

Las leyes podían tener principio en cualquiera de las Cámaras del Congreso, por proyectos presentados por sus miembros o por el poder ejecutivo nacional. El rastreo realizado alude nuevamente al peso de este último, quien dio inicio al elevado porcentaje de $71.92 \%$. La proyección de los gastos nacionales, cuyas discusiones hemos comenzado a analizar, también definió las prioridades en materia de conformación estatal. Llegados a este punto, resulta interesante entonces advertir los rasgos centrales de esta arquitectura legislativa y de su implementación práctica.

Antes de continuar, debemos señalar una cuestión de corte metodológico. Analizar el impacto de cada una de las disposiciones en las trece realidades provinciales que convergieron en la Confederación es una tarea dificultosa, no sólo por su complejidad y amplitud, sino también por la dispersión y disponibilidad de fuentes. ${ }^{30}$ No pretendemos entonces hacer un

${ }^{30}$ Cierto es que pese a que hemos triangulado una amplia gama de legajos éditos e inéditos de diversa índole $-y$ que existe un importante reservorio análisis exhaustivo sobre el ordenamiento militar, judicial, económico e ideológico interno e internacional y su puesta en práctica, sino que detallamos sólo el esquema general de las áreas que fueron atendidas en materia de legislación y gastos nacionales. Y profundizamos el estudio a partir de algunos casos concretos de la respuesta de las elites políticas provinciales a dicho ordenamiento.

\section{ALGUNOSOS CASOS CLAVE EN LA ACTIVIDAD Y RETROALIMENTACIÓN LEGISLATIVA: DIRIGENCIA, INSTITUCIONES Y ORGANISMOS ADMINISTRATIVOS PARA LA NACIÓN}

Como era de esperarse por la escasez de recursos humanos y económicos y por lo reciente de la conformación estatal, la capacidad efectiva que tuvo el gobierno nacional de hacer cumplir su voluntad fue reducida. Al igual que ha sido destacado para otras latitudes como México y Brasil, no debe confundirse entonces a una dirigencia política que consensuó un programa de modernización material e ins-

para el estudio del periodo-, el incendio de parte del archivo de la Confederación y la disgregación de material en las distintas provincias, nos impide respaldar algunos de nuestros argumentos con una mayor prueba documental. Existen fuentes incompletas o únicas para abordar algunos problemas, tal es el caso de la justicia federal que analizaremos luego, donde no contamos por ejemplo con un registro completo de la actividad de la Cámara Superior de Justicia que, como veremos, suplió en el periodo a la Corte Suprema de Justicia. Por otra parte, pese a la abundante e interesante producción historiográfica sobre las provincias a la que referimos, algunas de ellas aguardan aún un estudio pormenorizado que nos facilitaría un examen más fluido de los problemas que nos ocupan. 
titucional estatal con un Estado nacional poderoso. ${ }^{31}$

El proyecto político de una república federal con una legitimidad que reposara en el papel innovador de las instituciones encontró así resistencias. Que el Estado nacional ganara mayor densidad se conseguiría con la articulación de los intereses políticos y económicos que se dispersaban en las provincias con los proyectos acuñados en Paraná, y en este punto fue poco lo que pudo ser realizado.

Dicho contraste entre el plan centralizador y modernizador y sus posibilidades prácticas no impidió sin embargo que se fuera definiendo una esfera de acción para las instituciones estatales ni que en dicho marco se fuera constituyendo una dirigencia nacional. Se logró avanzar mediante las leyes sancionadas y las relaciones forjadas en el Congreso en la consolidación de los vínculos entre el poder nacional y los provinciales. Y en este devenir, como hemos comenzado a mostrar, se fueron conjugando los ideales e injerencia del ejecutivo nacional con el pragmatismo político y los intereses de las elites provinciales y de los legisladores y con las disposiciones tomadas por estos a raíz del debate parlamentario.

Las elites políticas provinciales fueron asumiendo entonces un proceso de modernización y de superación del ámbito provincial. ${ }^{32}$ Resulta sugerente recuperar, para

\footnotetext{
${ }^{31}$ Merino, Gobierno, 1998; Escalante, Ciudadanos, 1992, y Carvalho, Construção, 2007.

32 Responder al complejo y sugerente interrogante -planteado por uno de los evaluadores anónimos del artículo- de por qué las provincias aceptaron un espacio nacional cuya utilidad y eficacia al menos inicialmente no era clata, desde ya excede las posibilidades de este trabajo. Agradecemos dicha ad-
}

reflexionar sobre ello, una cuestión que ha sido recientemente destacada por Eduardo Míguez. El rico mapa bibliográfico de estudios provinciales sobre el periodo 1852-1880, ha mostrado que ya desde la década de 1850 en la mayoría de las provincias se fue reconstruyendo una elite política que dejaba atrás la etapa más clásica del caudillismo. El esquema conformado desde 1852 difería entonces bastante del anterior y ello fue así al menos por dos cuestiones planteadas por dicho autor.

Por un lado, porque como hemos comenzado a analizar y ampliaremos en adelante, el sistema constitucional no fue una mera formalidad. Por otra parte, porque los líderes locales y provinciales debían tomar en cuenta una interacción con el escenario nacional mucho más significativa que la desarrollada hasta entonces. Podían asumir que el proyecto integrador era una vía para potenciar su propio liderazgo y no ya el sometimiento a un centro. Conocían las posibilidades de obtener mayores recursos que los disponibles en sus espacios provinciales y de participar en los nuevos espacios de poder nacional. ${ }^{33}$

Consideramos que el Congreso nacional fue uno de esos espacios y que, en este marco, es importante volver sobre el perfil del personal político federal. La conformación de una dirigencia nacional que integró en su seno a las elites políticas provinciales fue fundamental para la viabilidad de la Confederación. Por sus cualidades aglutinadoras entre la primera y segunda mitad del siglo y su acumulación

vertencia y las interesantes problemáticas clave que nos fueron sugeridas. Planteamos respecto de ello sólo algunas reflexiones.

33 Estas ideas en Míguez, "Gestación", 2012, pp. $4-5$. 
de pericia en el manejo y la gestión política e institucional, pensamos que dicho personal y su acción en las instituciones nacionales constituyen un aspecto de importancia para entender por qué las provincias aceptaron el nuevo sistema político. Como ampliaremos enseguida, postulamos que ello representa también una clave de la herencia y amalgama de la Confederación con el proceso abierto en $1862 .{ }^{34}$

En efecto, se discutieron y circularon distintas ideas y definiciones sobre la forma estatal, se ensayaron formulas concretas de articulación, de participación y de preponderancia entre los poderes estatales y entre las esferas de poder nacional y provincial y se ideó una estructura institucional cuya puesta en práctica produjo algunos avances. ${ }^{35} \mathrm{Y}$ todo ello redundó en beneficio de un ejercicio político experimental, que realzó y dio sustancia al carácter de la formación estatal.

Retomemos entonces el análisis de los rasgos centrales de la arquitectura legislativa y de su implementación práctica, que es ilustrativo de lo que señalamos. ${ }^{36} \mathrm{Al}$ igual

\footnotetext{
34 Sobre este punto me permito citar nuevamente Lanteri, "Confederación", 2013.

${ }^{35}$ Como me ha señalado en el referato uno de los evaluadores, resta realizarse en este marco una explicación más cabal sobre la respuesta a dicho proceso modernizador, ya que el mismo incluía algunos aspectos desfavorables para la propia población que dichas autoridades representaban. Por ejemplo, la recepción de inmigrantes extranjeros que competirían con la mano de obra local y serían beneficiados con el reparto de tierra y la exención del servicio de armas que pesaba sobre dicha población local. Al respecto véase Djenderedjian, Gringos, 2008.

${ }^{36}$ En adelante análisis propio con base en datos y discusiones extraídas de Cámara de Diputados de la Nación, Poder, 1937, t. III, pp. 425-544, y t. IV, pp. 271 -725. Antes de continuar señalamos dos cues-
}

que para otros espacios iberoamericanos, la gran mayoría de los gastos de todo el periodo fue para el Ministerio de Guerra y Marina, quien obtuvo siempre más de $44 \%$ del total de lo presupuestado. Ello no llama la atención por el contexto de lucha contra el Estado de Buenos Aires por lograr la supremacía nacional. ${ }^{37}$ En contraste con dichas partidas presupuestarias, las leyes sancionadas representaron sólo $2 \%$ del total.

En segundo lugar se ubicó la cartera del Interior, con un promedio total de $25 \%$ de lo presupuestado y $31 \%$ de lo legislado. Se apuntó a distintos asuntos: a regular el funcionamiento institucional del Congreso -con medidas como las que

tiones. Por una parte, que nos referimos solamente a las leyes que fueron sancionadas. No contemplamos entonces los 133 proyectos de ley que no fueron aprobados. Por otro lado, debe ser aclarado que si tomamos como criterio las leyes sancionadas año tras año y no su organización en función de los ministerios nacionales es plausible establecer una subperiodización. Sin perder el horizonte del conflicto con el Estado porteño, hasta 1859 el Congreso estuvo orientado en buena medida a conformar una matriz institucional para el nuevo Estado. Por su parte, entre 1859 y 1861 se produjo un deslizamiento desde las leyes que apuntaban en su mayoría hacia "dentro" de la Confederación a la preponderancia de las asociadas a la lucha con el Estado porteño. La asunción de Santiago Derqui como presidente sucesor de Urquiza y los complejos vínculos entre ambos y con el por entonces gobernador de Buenos Aires Bartolomé Mitre -y luego presidente entre 1862 y 1868 - tiñeron el accionar legislativo. De las 89 leyes sancionadas en esos tres años, quince se refirieron específicamente a dicho conflicto y otras tantas apuntaron al fortalecimiento económico.

37 En dicho Estado, también fue el Departamento de Guerra el que ocupó el primer lugar en gastos y en personal en todo el periodo. Garavaglia, Construir, 2007, y "Rentas", 2010. 
indicamos en el primer apartado-, a garantizar la paz interna y la unidad nacional al resolver conflictos suscitados con el Estado porteño y los existentes en o entre las provincias y sancionar las Constituciones provinciales que uniformaron los marcos jurídicos con la Constitución nacional (36 leyes); a regular los transportes y comunicaciones (18 leyes) y a ordenar todo lo relativo a la administración estatal general (23 leyes).

En efecto, para incorporar las provincias a un plano de actuación y referencia nacional y reforzar la presencia estatal en el territorio, la creación de organismos administrativos de control formó parte de la agenda política. Las equiparaciones, reducciones y reacomodamientos que se les realizaron en el Congreso son una nueva muestra del interés por lo nacional, por materializar dicha esfera de la manera más conveniente aunque ello supusiera restringirlos o suprimirlos. Lo nacional, que había sido definido jurídicamente y tenía por ende su basamento en la Constitución federal y republicana de 1853 , era una cuestión difícil de llevar a la práctica política para las elites dirigentes provinciales.

Veamos los casos del Archivo General y de la Inspección General de Correos, Postas y Caminos, que fueron creados por ley nacional en septiembre 1856. La función de la Inspección era proponer desde la ciudad de Rosario -donde fue instalada por contar con uno de los puertos más importantes de la Confederación- al Ministerio del Interior todas las medidas que se creyeran convenientes para la mejora de estos tres ramos. ${ }^{38}$ En 1857 , en la y 500 .
Cámara de Diputados se presentó un proyecto de ley que propuso suprimirla basándose en razones de estricta economía.

La propuesta fue aceptada por el Congreso pero nuevamente el poder ejecutivo nacional hizo uso de su capacidad de veto. Adujo que coincidía en las razones de economía invocadas y en suspender el funcionamiento de la oficina. Sin embargo, su propuesta era no derogar la ley de creación porque ello supondría "declararla inútil o perjudicial cuando no lo era". La moción fue aceptada sin objeciones en el Congreso, por lo que la oficina quedó suspendida en sus funciones hasta que el erario permitiese retomarlas. ${ }^{39}$

Pese a ello, en el mismo año de 1857 los legisladores hicieron algunas modificaciones al presupuesto en materia de correos para que primara la "equidad y proporcionalidad" entre las provincias, cuestión que sus gobernadores les habían solicitado expresamente. Por ejemplo, se aceptó equiparar las partidas dadas a algunos trayectos provinciales porque las distancias y el trabajo de sus empleados eran iguales. A pedido de los diputados de San Juan también se agregó un correo en la provincia.

Este tipo de decisiones podrían ser leídas en función de la voluntad del gobierno nacional de mantener una imagen pública de eficacia y racionalidad ante las provincias. No era lo mismo derogar la ley que había creado un organismo que regulaba una de las demandas constitucionales -el establecimiento de postas y correos estipulado en el artículo 64-, que postular su suspensión transitoria. A su vez, que

${ }^{39}$ Discusión sobre el veto presidencial en Cámara de Diputados de la Nación, Poder, 1937, t. III, pp. 651-654. 
los legisladores "federalizaran" el sistema de transportes acorde a las solicitudes de las propias autoridades provinciales $\mathrm{da}$ cuenta de su voluntad de mantenerse comunicadas.

Por su parte, la función del Archivo fue conservar los documentos públicos nacionales para que generaciones venideras encontrasen "datos verídicos sobre los que contar la historia de la Confederación". ${ }^{40}$ Cada oficina pública nacional debía enviarle al finalizar el año todo documento producido en un "inventario prolijo y por duplicado". A casi dos años de su creación, también se resolvió posponer el Archivo hasta tanto el tesoro nacional estuviera "más desahogado".

Dicho esto, hay que subrayar la intención política de institucionalizar la comunicación y memoria nacionales que estuvo por detrás de la creación de estos organismos, aunque fuesen suprimidos. La problemática de la nación estuvo en el centro de los intercambios materiales y simbólicos que se pretendía apuntalar. La voluntad nacional quedaba así configurada como norma política. La producción y circulación de información fue considerada como un elemento estructurador del orden sociopolítico.

Como anticipamos, ello no fue sólo así para las autoridades de la Confederación sino también para sus sucesoras, quienes buscaron capitalizar el acervo de ideas, información y prácticas que allí se había forjado. Tanto la dinámica del funcionamiento político e institucional como la actuación de su personal político, fueron entonces consideradas de utilidad para la nueva etapa de conformación estatal nacional -ahora bajo la hegemonía de Buenos

${ }^{40}$ Registro Oficial, 1879, t. IV, pp. 107 y 511.
Aires-iniciada en 1862. Parte importante del personal político de la Confederación continuó ocupando una banca legislativa u otros puestos de la administración nacional. ${ }^{41}$ Pensamos entonces que dicho personal fue un nexo importante -y tal vez imprescindible- entre ambos periodos.

En este caso, el nuevo presidente Bartolomé Mitre ordenó que la documentación que se había recabado durante la vigencia del Archivo -así como el resto de la existente en Paraná- fuese trasladada a Buenos Aires tras la derrota de la Confederación por las fuerzas porteñas en la batalla de "Pavón". 42 Una situación similar se produjo respecto de la labor desarrollada en el ámbito estadístico y en el de la justicia federal.

El Departamento de Estadística, que se había creado en Paraná en 1856, fue unificado con la Oficina de Estadística Nacional por decreto presidencial en abril de 1864. Se nombró además como su director a Damián Hudson, quien en la Confederación había desarrollado múltiples funciones judiciales y administrativas

${ }^{41}$ Según el rastreo propio que realizamos, durante la presidencia de Bartolomé Mitre alrededor de $20 \%$ y en total entre 1862 y 1880 casi $32 \%$ de los legisladores del Congreso de la Confederación formaron parte del nuevo Congreso nacional. Datos en Cámara de Diputados de la Nación, Parlamento, 1948, pp. 296-411 y $418-447$

42 Biblioteca de la Nación, Pacificación, 1911, t. $\mathrm{x}$, entre otras, las pp. 90,99 y 112 . También fomentó el traslado a Buenos Aires de Carlos Saravia, secretario del Senado del Congreso de la Confederación desde 1854, a quien se consideró el "archivo vivo y ambulante" de dicho recinto. En efecto, continuó oficiando como secretario del nuevo Congreso -del que ahora participaba Buenos Aires- hasta su muerte en 1883. Semblanza en Mansilla, Retratos, 2005, pp. 106-107. 
(entre otras, en la propia Aduana de Entre Ríos). ${ }^{43}$

El fin principal del organismo había sido efectuar el censo nacional, que era otro de los requerimientos constitucionales. El gobierno envió una circular señalando los procedimientos para realizarlo a principios de 1857 . Los gobernadores debían nombrar comisiones de tres a cinco personas compuestas por ciudadanos idóneos mientras que todos los gastos serían costeados por el tesoro nacional. Precavido de las dificultades presentadas hasta entonces en otras áreas, el Departamento dio un detallado instructivo que reveló la falta de confianza del gobierno en la respuesta positiva de la población al censo.

Se alertó sobre el cuidado que se debía tener en preguntar y en aclarar sus buenas intenciones, que no eran recaudar dinero ni reclutar para el ejército sino sólo cumplir en toda su magnitud "con su alta misión administrativa" cuyo punto de partida era el censo. Además, se buscó que la sociedad se sintiera integrada en la tarea, señalando que este les permitiría elegir a los representantes que canalizarían sus demandas en el Congreso nacional. ${ }^{44}$

Las dificultades que se tuvieron muestran los límites de dicha cooperación. La mayoría de la población se opuso a responder a los cuestionarios mientras que los gobernadores manifestaron no contar con agentes suficientes para que actuasen en las comisiones. Ello no sólo produjo demoras en su realización sino que, además, provincias como San Juan, Jujuy, Salta y Catamarca directamente no lo efectuaron.

Finalmente en 1858 se resolvió suprimir las mesas de estadística provinciales

\footnotetext{
43.3 Mader, "Historia", 1968.

44 Registro Oficial, 1879, t. III, p. 437.
}

por la "esterilidad de los datos" enviados por las provincias a la mesa central de Paraná. Sin embargo, se decidió mantener a esta última y fortalecer su actividad, la que, como anticipamos, sirvió de base a la organización futura. Y es importante considerar además que la experiencia del censo de 1857 sirvió para desarrollar el primer censo nacional en $1869 .{ }^{45}$ Mitre se sirvió también de la experiencia de la Confederación en materia de justicia federal. Tomó la ley orgánica de 1858 -que enseguida analizaremos- como base de la sancionada en 1862 y también designó a parte de su personal político en puestos judiciales clave. ${ }^{46}$

El diseño y la dinámica de la justicia federal habían sido además funcionales para la propia conformación del orden político de la Confederación. Anticipamos en nuestra Introducción que los estudios específicos sobre el tema soslayaron dicha situación. En este marco, no centraron su atención en que la legislación sancionada en materia judicial fue parte de la puja de poder entre las provincias que se dio al interior del Congreso nacional. Tampoco analizaron la retroalimentación y contribución de dichas provincias al sistema judicial ni el accionar concreto que tuvo la Cámara Superior de Justicia -que suplió a la Suprema Corte de Justicia- y sus vínculos con los otros dos poderes estatales nacionales. ${ }^{47}$

En la disposición de los gastos nacionales el Ministerio de Justicia, Culto e

${ }^{45}$ Cámara de Diputados de la Nación, Poder, 1937 , t. IV, p. 489, y Maeder, "Historia", 1968.

46 Datos en Zavalía, Historia, 1920, p. 56, y Zimmermann, "Poder", 1998.

${ }^{47}$ Para un análisis más amplio de la justicia federal durante el periodo véase Lanteri, "Instituciones", 2011, y "Justicia", 2008. 
Instrucción Pública alternó el tercer y cuarto lugares con el de Hacienda, recibiendo cada uno un promedio de alrededor de $15 \%$ del total. Por el contrario al Ministerio de Hacienda le correspondió $44 \%$ de lo legislado. Sobre el punto no es necesario aclarar que poder estabilizar la precaria situación económica era imperioso para la viabilidad federal. Los recursos económicos eran indispensables para asentar los mecanismos de dominación y de administración nacional que se pusieron en marcha. ${ }^{48}$

Por su parte, 37 leyes -que representaron $13 \%$ de lo legislado- apuntaron a las tres áreas del Ministerio de Justicia, Culto e Instrucción Pública. Instaurar la justicia federal era crucial para la implantación práctica de la Constitución nacional que, como señalamos, había instituido un equilibrio entre los poderes estatales. Los principales pasos tendentes a tal fin fueron la sanción de la ley sobre "abogados nacionales" en 1855 -que según la Constitución nacional eran quienes debían integrar la justicia federal-y la ley orgánica de 1858.

Por entonces, los legisladores reflexionaron sobre un conjunto de temas articulados. Los mismos pueden reseñarse en la necesidad de lograr consenso para conformar a la justicia como el tercer poder estatal y de limitar sus funciones, en su poder

${ }^{48}$ Entre ellas, 40 estuvieron referidas a la sanción de los presupuestos nacionales cuyas cifras estamos sinterizando y más de 80 leyes orientadas a la implantación de un nuevo orden económico-financiero. Se reglamentó todo lo relativo a régimen de aduanas interiores y penalización del contrabando, empréstitos y bancos, contribución territorial y derechos diferenciales al comercio exterior, acuñación de monedas y uso del papel sellado, entre otros rubros. moderador frente a la población, en su papel para la unificación política y en la importancia de su función de control de los otros poderes estatales.

En el caso de la ley sobre "abogados nacionales", las tensiones políticas entre las propias provincias se hicieron muy visibles. La misma estipuló que no era necesario contar un grado universitario para ejercer dichos cargos. Muchos cordobeses vieron resentida su condición de abogados diplomados y, a la vez, se mostraron preocupados porque la Universidad de Córdoba -que había sido nacionalizada en mayo de 1854- perdiese legitimidad. Por ello intentaron que la ley no fuera sancionada.

Los legisladores que por el contrario votaron a su favor -y lograron que su postura prevaleciera - consideraron como una "embestida" la postura de los representantes de Córdoba contra las provincias del interior. Estas últimas no contaban con su misma tradición administrativa ni con recursos para afrontar la formación universitaria de su personal, pero tenían sus mismos derechos y atribuciones. ${ }^{49}$

$\mathrm{Y}$ dicha postura transparenta que el Congreso fue pensado como una institución federal que no debía reconocer particularismos ni favoritismos provinciales. Además, en dichos debates los legisladores actuaron como un elenco no diletante. Y ello no fue así sólo con motivo de este tema, sino también en lo que respecta a los demás conjuntos normativos. Señalamos, por ejemplo, en el apartado anterior, que tomaron la usanza de otros países para

49 Cámata de Diputados de la Nación, Poder, 1937 , t. vi, pp. $25-41$. Academia Nacional de la Historia-Unión Académique Internationale, Memorias, 2005 , p. 262. 
oponerse al veto que el poder ejecutivo intentó hacerle a la ley sobre los permisos para ocupar cargos a su servicio de 1857.

En efecto, los legisladores argumentaron y discutieron con base en la conformación institucional y política de la primera mitad de siglo pero también en la legislación provincial y en las doctrinas nacionales e internacionales contemporáneas y en las prácticas parlamentarias de otros países como Chile, Uruguay, Brasil, Francia, Estados Unidos e Inglaterra. ${ }^{50} \mathrm{La}$ construcción del Estado nacional llevó entonces a que el personal político se reconociera y actuara en la modernización estatal. Y que en dicho acontecer acumulara profesionalismo en el campo de la política y de la gestión de las instituciones estatales.

Por otra parte, pese a que la ley orgánica no pudo implementarse, la justicia federal fue parte del reparto de cargos implementado para seleccionar e integrar a las elites provinciales al Estado nacional. Y, por ende, operó en la práctica como un elemento efectivo de conformación de solidaridades políticas. ${ }^{51}$

50 Resulta imposible sintetizar los numerosos argumentos que se dieron por ejemplo en las más de quince sesiones en que se trató la ley orgánica de 1858. Valga como muestra que distintas voces se alzaron en contra del papel de "custodio" de la Constitución nacional que se le dio finalmente al poder judicial, porque temieron su omnipotencia sobre los otros dos poderes.

51 Datos de las designaciones en Archivo General de la Nación (en adelante AGN), x, Departamento de Justicia, Culto e Instrucción Pública, 1854-1860, 42-7-11. La ley sobre "abogados nacionales" tampoco pudo saldar el problema de la escasez de abogados, que se extendió a las décadas siguientes. Al respecto véase Zimmermann, "Education", 1999.
Por citar un ejemplo. De los 22 abogados residentes que la provincia de Córdoba informó tener en 1854 , casi un tercio pasó luego a desempeñar cargos en la administración nacional. El estudio de Pavoni ha mostrado que el poder judicial estuvo muy condicionado en la provincia por los enfrentamientos entre los otros dos poderes y por la injerencia de los gobernadores. ${ }^{52}$

En el marco de las designaciones políticas para los cargos judiciales que se sucedieron en el periodo, se originó un reclamo a la justicia federal de un camarista provincial removido de su cargo a finales de 1854. Si bien el conflicto remitía al contexto político cordobés, el camarista consideró que era la Corte Suprema de Justicia quien debía resolver el asunto.

Finalmente, el Congreso y el ejecutivo nacional afirmaron por medio de una ley no tener las competencias suficientes como para resolver el asunto porque los tribunales federales aún no estaban en funcionamiento. Pidieron previamente explicaciones al gobernador cordobés, quien informó que la remoción había sido legal porque el carácter de su cargo era interino y que la legislatura estaba de acuerdo. ${ }^{53}$

Aunque el caso no tuvo resolución en el periodo, lo interesante es que el camarista cordobés había librado la resolución del asunto a la Corte Suprema de Justicia. Y ello revela una demanda temprana de la intervención activa de la justicia federal para dirimir un conflicto provincial. La justicia federal comenzó así a ser reconocida por las provincias como un árbitro de poder externo. Gestos como el del

52 Pavoni, Córdoba, 1993.

5.3 Cámara de Diputados de la Nación, Poder, 1937, t. VI, pp. 51-55. 
camarista cordobés que acabamos de citar, tuvieron lugar en diversas ocasiones.

Al elevar casos conflictivos para su resolución, se dieron argumentos contundentes en este sentido. Como ilustración vale la pena citar, entre los disponibles, uno que es de suma importancia para visualizar la manera en que la pertenencia a una entidad política-judicial mayor iba calando en los sistemas políticos provinciales. Las provincias apelaron en este caso a la justicia federal ante posibles problemas que pudieran surgir con sus funcionarios judiciales y no para dirimir un conflicto puntual.

En mayo de 1856, Jujuy, Salta y Tucumán celebraron un tratado con la voluntad de "unirse en un solo círculo o distrito judicial" y de incorporar en este a Santiago del Estero y Catamarca. Esta última provincia aceptó conformarlo porque al igual que las demás, entendía que era útil y conveniente para sus propios intereses (sobre todo económicos).

La propuesta era crear, sobre la base de las atribuciones del artículo 104 de la Constitución nacional -que permitía a las provincias celebrar tratados parciales para fines de administración de justicia y otras materias- un Tribunal Superior Común de Justicia, que resolviese, en última instancia, todas las causas civiles y criminales de sus jurisdicciones. $Y$ que sometiera -por vía de prórroga de jurisdicción-, las causas de responsabilidad contra los miembros del Tribunal a la Corte Suprema de Justicia.

Pese a que el tribunal funcionó por poco tiempo, acciones de este tipo realzaban y daban sustancia al carácter federal de la formación estatal. Es interesante ver que las provincias proyectaron que la asociación entre ellas en primer lugar y luego con una institución nacional, era positiva para sus propios intereses. ${ }^{54}$

Y ello no llama la atención si se tiene en cuenta el precario estado de sus administraciones. Aludimos ya a la preocupación por recibir subsidios por parte del gobierno nacional y a la carencia de abogados. A ello se sumaba la falta de independencia de los funcionarios judiciales y las limitaciones en el ejercicio efectivo de la justicia, que apuntamos para el caso de Córdoba, pero que también fue señalada una y otra vez en los distintos espacios provinciales. ${ }^{55}$

Asimismo, debe ser destacado que la clave regional que se planteó en la conformación del tribunal de las provincias del norte no era propia de la década. Se proyectó una práctica anterior de institucionalización de vínculos y referencias regionales, que se había materializado entre estas provincias en alineaciones como

${ }^{54}$ En efecto, la iniciativa tuvo también buena recepción en otros espacios provinciales. Así, un diputado nacional propuso al gobernador correntino hacer lo mismo entre Santa Fe, Corrientes y Entre Ríos. Le informó además que ya había evaluado la opinión entre sus pares y que era positiva. Incluso, afirmó que había podido conversar con Urquiza al respecto, quien había estado en total acuerdo. El gobernador lo autorizó para accionar en dicho sentido, aunque finalmente la iniciativa no se concretó. De Vicente Quesada al gobernador Pujol, Paraná, 12 de julio de 1856 y respuesta, en Pujol, Corrientes, 1911, t. VI.

${ }^{55}$ Por ejemplo, el ministro de Gobierno de San Juan y diputado nacional por la provincia comunicaba que "cada empleado exige y si no se le concede apela a su arma favorita: una renuncia, y como los hombres son pocos y menos los capaces y el gobierno dice amén”, De Manuel Antonio Durán a Benjamín Victorica, San Juan 15 de febrero de 1856, en AGN, vi, Benjamín Victorica, Diputado al Congreso federal en $1856,3131$. 
el "Protectorado de Heredia" en los treinta y la "Coalición del Norte" de 1840.56

En este sentido, la conformación del tribunal se vio facilitada porque tanto los gobernadores de las provincias signatarias como sus representantes no eran personas ajenas a la vida política nacional ni provincial. Y aquí vislumbramos un caso concreto de la reorientación por parte del personal político de su experiencia e información forjadas durante la primera mitad del siglo al servicio de la Confederación. ${ }^{57}$

Lo novedoso del caso analizado parecía residir entonces en la solicitud de que la Corte Suprema de Justicia entendiese en las causas de responsabilidad contra los miembros del tribunal y, por ende, en la función integradora y reguladora dada a la justicia federal. Con respecto a esto último, el análisis del debate que tuvo lugar en el Congreso con motivo del permiso que se le solicitó para conformar el tribunal, ilustra también sobre la relación efectiva entre los poderes estatales.

Allí, los legisladores manifestaron no tener la competencia suficiente para expedirse sobre el accionar del poder judicial. ${ }^{58}$ Luego de una votación ajustada -en principio empatada y luego definida por dos

56 Para un análisis de ambos véase Macías, "Armas", 2007.

57 Por cuestiones de espacio no desarrollaremos sus biografías. Valga como muestra que José Benito Bárcena, Juan de Dios Usandivaras y Salustiniano Zavalía, los tres representantes que firmaron el tratado habían desempeñado funciones políticas y/o judiciales con anterioridad a 1851 e incluso Zavalía había conformado la "Coalición del Norte" en 1840.

${ }^{58}$ En adelante, el debate consúltese en Cámara de Diputados de la Nación, El poder legislativa, 1937, t. vI, pp. 338-347. Beatriz Bosch presentó esta discusión pero no desde el enfoque que aquí nos interesa destacar, Bosch "Poder", 1964. votos-, el Congreso decidió aprobar la conformación del tribunal, pero negó la atribución conferida a la Corte Suprema de Justicia de entender sobre la responsabilidad de sus miembros.

Creyeron que dar dicha atribución resentiría a las soberanías provinciales al no estar contemplada la situación por la Constitución nacional. Y que sería además injusto, dada la objeción que se les había hecho a algunas provincias de que los miembros de sus respectivas Cámaras de Justicia fueran juzgados por la Corte Suprema. Debían como dirigentes estatales mostrarse "escrupulosos" en todos los casos y no tener favoritismos.

La relación esbozada en este ejemplo, en particular entre los poderes estatales y entre las esferas nacional y provincial, tuvo en otros casos que hemos podido reconstruir distintos pormenores y vicisitudes. Las ambigüedades provocadas por el complejo funcionamiento de la justicia federal, con una Cámara Superior de Justicia que suplía a la Corte Suprema pero que no tenía sus mismas atribuciones constitucionales, ${ }^{59}$ una ley orgánica sin implementación, el peso de las prácticas políticas pasadas que dificultaron la racionalidad administrativa ${ }^{60}$ y con escasos

${ }^{59}$ La Cámara Superior de Justicia funcionó en Paraná entre 1854 y 1861 como tribunal de consulta y apelaciones de la Confederación. El fiscal de Estado era parte legítima en todos los negocios criminales y en los civiles en los que se interesaba la causa pública o la jurisdicción nacional, en los recursos de fuerza y en los recursos extraordinarios o de competencias entre diversas jurisdicciones.

${ }^{60}$ Por citar un caso. En clara sintonía con las demás leyes que apuntaron a conformar un orden económico-financiero estable, en 1856 se facultó a los administradores nacionales de Rentas y Aduanas a entender en primera instancia en materia de contra- 
recursos económicos que impedían corporizarla, dejaban al ejecutivo nacional la posibilidad de intervenir en los asuntos contenciosos que enfrentaban a las provincias. Y claro, también, de valerse de dicha situación para obtener réditos políticos.

A diferencia del caso del camarista cordobés donde el ejecutivo (y el Congreso) directamente aludió a la falta de instalación de poder judicial federal, en otras situaciones intervino activamente y legitimó su accionar en las recomendaciones de la Cámara Superior de Justicia, que actuó en solidaridad con sus demandas. ${ }^{61}$

bando y demás causas contenciosas de Hacienda. La Cámara Superior de Justicia quedó por su parte autorizada a conocer en segunda instancia en las causas que le fuesen elevadas en apelación o remitidas en consulta. Esta centralización en materia judicial fue objetada por algunas personas que señalaron que la falta de hábitos administrativos y el comportamiento de los comerciantes irían en detrimento del objetivo inicial. Entre ellos, de Juan de Dios Usandivaras a Juan María Gutiérrez, Salta 21 de mayo de 1855, Biblioteca del Congreso de la Nación, Arbivo, 1981, t. III, pp. 262-264.

6! Así lo hizo, por ejemplo, con motivo de un conflicto en la provincia de San Juan por el ejercicio del Patronato. Con la intención de favorecer al ex gobernador y por entonces comandante de la División Militar del Oeste de la Confederación-Nazario Benavídez-, se opuso al accionar del gobernador Díaz. También actuó la Cámara de Justicia en connivencia con el poder ejecutivo nacional y con el propio Congreso en contra de Evaristo Carriego, a quien se le creó una causa por "abuso de autoridad". Carriego había puesto en disputa el poder de Urquiza al ganarle en 1858 las elecciones como diputado nacional por el Territorio Federalizado a Benjamín Victorica, yerno de Urquiza y su principal vocero en el Congreso desde 1856. Véanse casos en Instituto de Investigaciones de Historia Regional y Argentina "Profesor Héctor Domingo Arias", Archivo, 2007, t. v, pp. 307-309 y 313-314; El Nacional Argentino, 17 de febrero de 1857, y Coronado, Misterios, 1866, t. I, pp. 31-41.
Pero el juego político que surgió en la resolución por parte de dicha Cámara de los pocos casos de los que disponemos datos, no reveló sólo relaciones de connivencia sino también de tensión entre los poderes estatales. En efecto, los miembros de la justicia federal no estuvieron siempre bajo estricta órbita del poder ejecutivo nacional sino que, incluso, se mostraron recelosos cuando se sintieron privados en sus atribuciones. ${ }^{62}$

Para finalizar resulta interesante recuperar el ámbito de las relaciones exteriores. Como anticipamos, las autoridades pensaron que una de las maneras de fortalecer el poder estatal se lograría por el reconocimiento de su soberanía. El Ministerio de Relaciones, sin embargo, fue el que menos dinero recibió en todo el periodo, con porcentajes que no superaron $4 \%$ del presupuesto. En complemento con ello, $10 \%$ del total de las leyes sancionadas se orientó a reglar los vínculos con las potencias extranjeras, especialmente a ratificar tratados de comercio, amistad y libre navegación.

El poco dinero presupuestado fue acorde al diseño dual que se estableció. Se instalaron pocas legaciones permanentes en el exterior - la de Alberdi en Europa, una en Chile y otra en Montevideo- a las que se sumó en cambio una densa red de consulados. Se instalaron así en la Confederación cónsules y agentes comerciales de varios países europeos y americanos, cuyo accionar estuvo coor-

62 Véanse casos en Cámara de Diputados de la Nación, Poder, 1937, t. vI, pp. 10 y 56 , y del ministro de Justicia, Culto e Instrucción Pública al presidente de la Cámara Superior de Justicia, Paraná, 24 de febrero de 1857, en AGN, X, Departamento de Justicia, 1857-1858, 44-8-4. 
dinado por oficinas administrativas del ministerio.

Estas medidas no fueron suficientes para lograr los fines propuestos. A pesar del reconocimiento que logró Juan Bautista Alberdi de la Confederación como Estado independiente por parte de las principales potencias europeas, no se obtuvo un apoyo internacional eficiente. Además, los agentes extranjeros acostumbrados a otro estilo de vida prefirieron residir en Buenos Aires que en Paraná. ${ }^{63}$ En su correspondencia privada Alberdi narró las peripecias de su actividad. Sus cartas remiten a reclamos de diversa índole: falta de información sobre la situación nacional, de instrucciones para su labor y de personal de apoyo para realizarla. Todo lo cual veía de peor manera en un plano comparativo con el protocolo de las cortes europeas. ${ }^{64}$

Terminar este trabajo con la descripción de Alberdi no resulta circunstancial. Como advertimos, la experiencia social, política y cultural lo había llevado hacia 1852 a una reformulación entre la teoría y la práctica republicana y federal. Afirmó que la república reconocía muchos grados y se prestaba a las exigencias de la edad y del espacio. Por esta concepción había esbozado una compleja articulación entre los poderes estatales y propuesto una serie de elementos que permitirían culminar el tránsito hacia una "república verdadera". 65

En definitiva, consideramos que durante el periodo se fue materializando la 1994.

${ }^{63}$ Scobie, Lucba, 1964, y Brezzo, "Intimidades",

${ }^{64}$ Entre otros, de Juan Bautista Alberdi a Juan María Gutiérrez, París, marzo de 1856, en Alberdi, Cartas, 1953, p. 64.

${ }^{65}$ Canal, Constitución, 1986, p. 136. "república posible" que Alberdi había definido. En la Confederación se establecieron relaciones e instituciones que fueron integrando a las provincias en un sistema de poder nacional.

\section{CONCLUSIONES}

La descripción que hemos realizado en este trabajo es en gran medida ilustrativa de la convicción de las autoridades nacionales de que la modernización política, social y económica era imposible sin un entramado jurídico e institucional que la sustentase. Tuvieron como objetivo conformar un nuevo Estado y para ello gestionaron un proceso de transformación que encontró serias dificultades políticas, económicas y sociales al momento de su implementación.

Se debió lidiar con las necesidades y urgencias que le planteaba su ajuste a la realidad de la Confederación. Los principales obstáculos fueron la falta de recursos económicos y humanos y de hábitos y prácticas, dada la reciente conformación estatal. Este andamiaje fue entonces mucho menos exitoso de lo que algunos autores -centrados más en describirlo que en atender a su ejecución- señalaron. ${ }^{66}$

De hecho, a diferencia de los estudios específicos sobre el periodo, en este trabajo centramos nuestra atención en la convergencia de las dinámicas provincial y nacional para explicar esta trama política e institucional. Revelamos que las provincias y sus representantes fueron protagonistas activos del proceso. Dicha situación se hizo claramente visible a partir del

${ }^{66}$ Ruiz, Centenarios, 1952; Macchi, Primera, 1979, y Bosch, Urquiza, 1980. 
diseño y funcionamiento que tuvieron el Congreso nacional, y subsidiariamente, la justicia federal y algunos de los principales organismos estatales.

Las provincias hallaron en el Congreso un marco institucionalizado en el cual pudieron construir y ejercer su poder; impulsaron allí sus dificultades, ideas e intereses propios. Advertimos que los legisladores ajustaron sus deberes y atribuciones a los de los otros dos poderes estatales. Las situaciones descritas dejaron al descubierto que la división de poderes surgió como producto de una decisión política. No siempre hubo relaciones de connivencia sino también de tensión entre estos. Y dicho ajuste de atribuciones fue modelando una dirigencia nacional.

Mostramos que los ideales e injerencia del poder ejecutivo nacional se conjugaron con el pragmatismo político y los intereses de las elites políticas provinciales y de los legisladores. En este marco, revelamos los problemas concretos que se tuvieron en la aceptación por parte de las provincias del funcionamiento de los órganos administrativos estatales. Señalamos además que ello afectó el propio funcionamiento institucional del Congreso, por la falta de personal administrativo que agilizara su labor y por las dificultades en conformar el quórum legal para sesionar. Y, también, referimos a los problemas existentes en la instauración de la justicia federal.

Sin embargo, ello no supuso que la Confederación estuviera reducida a un estado de falencia institucional como se ha postulado, ${ }^{67}$ sino que las provincias tuvieron registro de que había instituciones estatales que las contenían; la Consti-

\footnotetext{
${ }^{67}$ Entre otros Gorostegui, Organización, 1972, y Oszlak, Formación, 1997.
}

tución nacional y el Congreso y la justicia federal les interesaron. Fueron ámbitos de cristalización de conflictos y de juegos, alianzas políticas provinciales y nacionales.

La Confederación fue la primera parte de un proceso de formación estatal que encontró un acto final hacia 1880, cuando con la federalización de la ciudad de Buenos Aires fue disminuyendo la preeminencia que había tenido la provincia de Buenos Aires desde 1820 en el concierto nacional. ${ }^{68}$ En efecto, aunque los organismos e instituciones estatales no pudieron ganar en la solidez que las autoridades esperaban lograr, resulta notable que las cuestiones expuestas en este artículo remiten a un sugestivo grado de cohesión y de referencialidad al espacio nacional.

Fue grande el esfuerzo por construir una estructura estatal centralizada y modernizante, aunque no se tuvieron los recursos ni el tiempo suficientes para terminar de institucionalizar los órganos del Estado requeridos para desarticular más de 30 años de funcionamiento provincial autónomo. Tampoco fue exitoso el intento de construir un Estado con dirección política en Entre Ríos. Pero las provincias comenzaron a entenderse y a asumirse en una forma federal y republicana y las autoridades a construirse en una dirigencia política con proyección nacional.

Lo principal fue que, en este devenir, el juego institucional fue reconocido y se fue imponiendo como una forma de articulación política. Por ello pensamos que la nación se fue emplazando como la base de la acción y la legitimidad política y los dirigentes se fueron identificando con la

${ }^{68}$ Bragoni y Míguez (coords.), Nuevo, 2010 , p. 27. 
estructura estatal nacional que ellos mismos construían. ${ }^{69} \mathrm{Y}$ consideramos, en definitiva, que todo ello revela la importancia y funcionalidad que tuvo el periodo de la Confederación en el camino de la profesionalización política y de la materialización de una soberanía nacional.

\section{Fuentes Consultadas}

Archivos

AGN Archivo General de la Nación, Buenos Aires, Argentina.

AgER Archivo General de Entre Ríos, Paraná, Argentina.

\section{Hemerografía}

El Nacional Argentino, Paraná, 1854-1861.

\section{Bibliografía}

-Academia Nacional de la Historia-Unión Académique Internationale, Memorias de una sociedad criolla. El diario de Ramón Gil Navarro 1845 1856, Academia Nacional de la Historia, Buenos Aires, 2005.

- Alberdi, Juan Bautista, Cartas inéditas a Juan Maria Gutiérrez y a Félix Frías, Luz del Día, Buenos Aires, 1953.

, Bases y puntos de partida para la organización política de la República Argentina, Plus Ultra, Buenos Aires, 1991 [primera edición 1852].

${ }^{69}$ Para Oscar Oszlak, en la Confederación la provincia constituyó el principal marco de referencia para la organización política y las relaciones sociales. Oszlak, Formación, 1997, especialmente pp. 45 y 62.
- Angueira, María del Carmen, El proyecto confederal y la formación del Estado nacional (18521862), CEAL, Buenos Aires, 1989, 3 vols.

-Annino, Antonio (coord.), Historia de las elecciones en Iberoamérica, siglo XIX. De la formación del espacio político nacional, FCE, Buenos Aires, 1995.

-Biblioteca de la Nación, Paifficación y reorganización nacional después de Pavón, BN, Buenos Aires, 1911, t. X.

- Biblioteca del Congreso de la Nación, Archivo del doctor Juan Maria Gutiérrez. Epistolario, BCN, Buenos Aires, 1981, tt. II, III y IV.

-Bosch, Beatriz, "El poder judicial en la Confederación Argentina (1854-1861)", Revista del Instituto de Historia del Derecho Dr. Ricardo Levene, núm.15, 1964, Buenos Aires, pp. 2-28. Aires, 1980. Urquiza y su tiempo, EUDEBA, Buenos

-Botana, Natalio, El orden conservador, Sudamericana, Buenos Aires, 1977.

-Bragoni, Beatriz, Los bijos de la revalución. Familia, negocios y poder en Mendoza en el siglo XIX, Taurus, Buenos Aires, 1999.

y Eduardo Míguez (coords.), Un nuevo orden político. Provincias y Estado nacional, 18521880, Biblos Historia, Buenos Aires, 2010.

-Brezzo, L. M., Cartas de Alfredo Marbais Du Graty a Juan Bantista Alberdi, UCA, Rosario, 1988.

-Brezzo, Liliana, "Intimidades de una diplomacia: el Ministerio de Relaciones Exteriores de la Confederación (1854-1860)", Todo es Historia, núm. 322, 1994, pp. 76-88.

-Buchbinder, Pablo, Caudillos de pluma y bombres de ación. Estado y politica en Corrientes en tiempos de la organización nacional, Prometeo, Buenos Aires, 2004.

-Cámara de Diputados de la Nación, El poder legislativo de la nación argentina por Carlos Alberto Silva, BCN, Buenos Aires, 1937, tt. I al vi.

El parlamento argentino, 1854-1947, BCN, Buenos Aires, 1948. 
-Canal Feijó, Bernardo, Constitución y revolución; Juan Bautista Alberdi, Hyspamérica, Buenos Aires, 1986.

-Carmagnani, Marcello (coord.), Federalismos latinoamericanos: México, Brasil, Argentina, FCE, México, 1993.

\section{- Estado y meriado. La economía pública} del liberalismo mexicano, 1850-1911, El Colegio de México/FCE, México, 1994.

-Carvalho, José Murilo de, A construção da orden: a elite politica imperial. Teatro de sombras: a política imperial, Cavilação Brasileira, Río de Janeiro, 2007.

-Chiaramonte, José Carlos, Nación y Estado en Iberoamérica, Sudamericana, Buenos Aires, 2004.

-Coronado, Juan, Misterios de San José. Escenas de la vida del general Justo José de Urquiza, explicadas y comentadas por Juan Coronado, Imprenta de la Sociedad Topográfica, Buenos Aires, 1866, c. 1.

-Djenderedjian, Julio, Gringos en las pampas. Inmigrantes y colonos en el campo argentino, Sudamericana, Buenos Aires, 2008.

-Escalante Gonzalbo, Fernando, Ciudadanos imaginarios, COLMEX, México, 1992.

-Garavaglia, Juan Carlos, Construir el Estado, imventar la nación: el Río de la Plata, siglos XVIIIXIX, Prometeo, Buenos Aires, 2007.

, "Rentas, deuda pública y construcción estatal: la Confederación argentina, 18521861", Desarrollo Económico, vol. 50, núm. 198, julio-septiembre de 2010, pp. 223-248.

-Goldman, Noemí (ed.), Lenguaje y revolución. Conceptos políticos clave en el Río de la Plata, 1780-1850, Prometeo, Buenos Aires, 2008.

-González Bernaldo de Quirós, Pilar, Civilidad y politica en los origenes de la nación argentina. Las sociabilidades en Buenos Aires, 1829-1862, FCE, Buenos Aires, 2000.

-Gorostegui de Torre, Haydeé, La organización nacional, Paidós, Buenos Aires, 1972.

-Instituto de Investigaciones de Historia Regional y Argentina "Profesor Héctor Do- mingo Arias", Arcbivo del Brigadier general Nazario José Bencwídez, Universidad de San Juan, San Juan, 2007, t. v.

-Lanteri, Ana Laura, "La justicia federal en la 'Confederación' argentina (1854-1861). Apuntes sobre un intento de articulación entre nación y provincias", Territórios e Fronteiras, vol.1, núm. 1, ICHS/UFMT, Brasil, 2008, pp. 26-50.

"La conformación de una dirigencia nacional. Notas sobre la dinámica legislativa del Congreso de Paraná (1854-1861)" en Valentina Ayrolo (comp.), Economía, sociedad y política en el Río de la Plata del siglo XIX. Problemas y debates, Prohistoria, Rosario, 2010, pp. 125-139.

"De lo ideal a lo posible. Dirigencia e instituciones nacionales en la 'Confederación' (1852-1862)", tesis doctoral, Universidad Nacional del Centro de la Provincia de Buenos Aires, Tandil, Argentina, 2011.

"Instituciones estatales y orden político. Diseño, prácticas y representaciones de la justicia federal en la 'Confederación' (18521862)”, Población y Sociedad. Revista Regional de Estudios Sociales, vol. 18, núm. 1, 2011, Tucumán, pp. 49-78.

, "Las provincias en un ámbito de poder institucionalizado. Representación política y acción legislativa en el Congreso de Paraná en la 'Confederación' (1854-1861)”, Estudios Socicles, núm. 41, 2011, Santa Fe, pp. 69-82.

" "Unos cuantos aventureros de la política'. Notas sobre los 'alquilones' en la 'Confederación' (1854-1861)", PolHis. Boletín Bibliográfico Electrónico, núm. 7, 2011, Buenos Aires, pp. 115-126.

, 'Ia 'Confederación' desde sus actores.

La conformación de una dirigencia nacional en un nuevo orden político (1852-1862)" en Ana Laura Lanteri (coord.), Actores e identidades en la construcción del Estado nacional (Argentina, siglo XIX), Teseo, Buenos Aires, 2013, pp. 129-171.

-Lettieri, Alberto, La construcción de la república de la opinión, Buenos Aires frente al interior en 
la década de 1850, Prometeo, Buenos Aires, 2006.

-Macchi, Manuel, Primera presidencia constitucional argentina, Ediciones del Palacio San José, Entre Ríos, 1979.

-Macías, Flavia, "Armas y política en el norte argentino. Tucumán en tiempos de la organización nacional", tesis doctoral, Universidad Nacional de La Plata, Argentina, 2007.

-Maeder, Ernesto, "Historia y resultados del censo confederal de 1857", Trabajo y Comunicaciones, núm. 18, 1968, Buenos Aires, pp. 2-28.

-Mansilla, Lucio, Retratos y recuerdos, Paradiso, Buenos Aires, 2005 [la. ed., 1894].

-Mega, Aixa, "La Confederación Argentina (1852-1861), ¿un proyecto de institucionalidad trunco?", Hablemos de Historia, núm. 6, 2010, Entre Ríos, pp. 195-207.

-Merino Huerta, Mauricio, Gobierno Local, pader nacional: la contienda por la formación del Estado mexicano, Colmex, México, 1998.

-Míguez, Eduardo, "Gestación, auge y crisis del orden político oligárquico en la Argentina. Balance de la historiografía reciente", PolHis. Boletín Bibliográfico Electrónico, núm. 8, 2012, Buenos Aires.

-Oszlak, Oscar, La formación del Estado argentino, Planeta, Buenos Aires, 1997.

-Páez de la Torre, Carlos, El derrumbe de la Confederación, 1855-1862, La Bastilla, Buenos Aires, 1984.

-Palacios, Guillermo (coord.), Ensayos sobre la nueva bistoria política en América Latina, siglo xix, Colmex, México, 2007.

-Pavoni, Norma, Córdoba y el gobierno nacional, Editora Suárez, Córdoba, 1993.

-Paz, Gustavo,"El gobierno de los 'conspicuos': familia y poder en Jujuy, 1853-1875" en Hilda Sabato y Alberto Lettieri (comps.), La vida política del siglo XIX. Armas, votos y voces, FCE, Buenos Aires, 2003, pp. 223-241.

-Pujol, Juan, Corrientes en la organización nacional, Kraft, Buenos Aires, 1911, tt. VI y IX.
- Registro Oficial de la República Argentina que comprende los documentos expedidos desde 1810 basta 1873, La República, Buenos Aires, 1879, tt. III Y IV.

-Roldán, Darío, "La cuestión liberal en la Argentina del siglo xux. Política sociedad, representación" en Beatriz Bragoni y Eduardo Míguez (coords.), Un nuevo orden político. Provincias y Estado nacional, 1852-1880, Biblos Historia, Buenos Aires, 2010, pp. 275-293.

-Ruiz Moreno, Leandro, Centenarios del promunciamiento y de Monte Caseros, Nueva Impresora, Entre Ríos, 1952.

-Sabato, H. (coord.), Ciudadanía politica y formación de las naciones. Perspectivas bistóricas de América Latina, COLMEX /FCE, México, 1997.

-Schmit, Roberto, Historia del capitalismo agrario V. Los límites del progreso: expansión rural en los origenes del capitalismo rioplatense, Entre Ríos, 1852-1872, Siglo XXI, Buenos Aires, 2008.

-Scobie James, La lucha por la consolidación de la nacionalidad argentina, 1852-1862, Hachette, Buenos Aires, 1964.

-Taboada Gaspar, Los Taboada. Luchas de la organización nacional, Libreros Editores-Bernabé y Cía., Buenos Aires, 1937, tt. uI y IV.

-Zavalía, Clodomiro, Historia de la Corte Suprema de Justicia de la República Argentina en relación con su modelo americano, Taller Peuser, Buenos Aires, 1920.

-Zimmermann, Eduardo, "El poder judicial, la construcción del Estado y el federalismo: Argentina, 1860-1880" en Eduardo PosadaCarbó (ed.), In Search of a New Order: Essays on the Politics of Nineteenth-Century Latin Anerica, ILAS, Londres, 1998, pp. 131-152. , "The Education of Lawyers and Judges in Argentina's Organización Nacional (1860-1880)" en Eduardo Zimmermann (ed.), Judicial Institutions in Nineteenth Century Latin America, University of London, Londres, 1999, pp. 104-123. 